\title{
Coulomb Constitutive Laws for Friction: Contrasts in Frictional Behavior for Distributed and Localized Shear
}

\author{
Chris Marone ${ }^{1}$, B. E. Hobbs ${ }^{2}$ and A. Ord ${ }^{2}$
}

\begin{abstract}
We describe slip-rate dependent friction laws based on the Coulomb failure criteria. Frictional rate dependence is attributed to a rate dependence of cohesion $c$ and friction angle $\phi$. We show that differences in the stress states developed during sliding result in different Coulomb friction laws for distributed shear within a thick gouge layer versus localized shear within a narrow shear band or between bare rock surfaces. For shear within gouge, shear strength is given by $\tau=c \cos \phi+\sigma_{n} \sin \phi$, whereas for shear between bare rock surfaces the shear strength is $\tau=c+\sigma_{n} \tan \phi$, where $\tau$ and $\sigma_{n}$ are shear and normal stress, respectively. In the context of rate-dependent Coulomb friction laws, these differences mean that for a given material and rate dependence of the Coulomb parameters, pervasive shear may exhibit velocity strengthening frictional behavior while localized shear exhibits velocity weakening behavior. We derive from experimental data the slip-rate dependence and evolution of $c$ and $\phi$ for distributed and localized shear. The data show a positive rate dependence for distributed shear and a negative rate dependence for localized shear, indicating that the rate dependence of $c$ and $\phi$ are not the same for distributed and localized shear, even after accounting for differences in stress state. Our analysis is consistent with the well-known association of instability with shear localization in simulated fault gouge and the observation that bare rock surfaces exhibit predominantly velocity weakening frictional behavior whereas simulated fault gouge exhibits velocity strengthening followed by a transition to velocity weakening with increasing displacement. Natural faults also exhibit displacement dependent frictional behavior and thus the results may prove useful in understanding the seismic evolution of faulting.
\end{abstract}

Key words: Friction, Coulomb failure, constitutive laws, localized shear.

\section{Introduction}

Friction laws that incorporate slip-rate dependence and memory (state) effects (DIETERICH, 1979, 1981; RUINA, 1983) have proven successful in describing a range of observations from laboratory experiments and natural faults. These include: (1) the time and slip-rate dependence of laboratory friction data (DIETERICH, 1979) and the stability of sliding in laboratory samples (Shimamoto, 1986; Tullis and WeEks, 1986; CoX, 1990; WoNG et al., 1991), (2) the depth variation of slip

\footnotetext{
' Department of Earth, Atmospheric, and Planetary Sciences, Massachusetts Institute of Technology, Cambridge, MA, U.S.A.

${ }^{2}$ CSIRO Division of Geomechanics, Mt. Waverley, Victoria, Australia.
} 
stability on natural faults (TSE and RICE, 1986; MARONE and SCHOLz, 1988; BLANPIED et al., 1991), (3) the critical slip distance of seismic faulting (DIETERICH, 1986; SCHOLz, 1988), and (4) the relation between seismic and postseismic phenomena (RICE and GU, 1983; MARONE et al., 1991). In spite of this, we know little about the underlying physics controlling rate and state dependent rock friction and thus the parameters of these laws remain empirical.

Progress toward understanding the micromechanics of rate dependent friction has been greatest for initially-bare rock surfaces. Experimental data show an instantaneous change in friction upon a change in slip velocity followed by a displacement dependent evolution (see above references). DIETERICH (1979) and DIETERICH and CONRAD (1984) interpreted the instantaneous effect as a strain-rate dependence of rock strength and suggested that the friction evolution effect represents an evolving real area of contact. They proposed that this evolution results from replacement of existing contacts by those appropriate to the new slip velocity.

Although these interpretations are supported by recent work showing direct correlations between changes in friction and real area of contact for lucite plastic (KILGORE and DIETERICH, 1991), many details of the underlying processes remain unclear. Moreover, for natural faults the effects of variables such as temperature, normal stress, rock type, and damage (CHESTER and HigGS, 1992; LINKER and DieTERICH, 1992; RIENEN et al., 1992; StEACY and SAMmIs, 1992) may render these simple interpretations incomplete, further complicating the problem of scaling empirical parameters from the laboratory to natural faults.

The Coulomb failure criterion offers an alternative framework within which to evaluate velocity dependent friction. The Coulomb criterion relates frictional strength to cohesion and friction angle (angle of internal friction), a parameter which describes the normal stress dependence of shear strength (e.g., HANDIN, 1969). In a Coulomb law, frictional rate dependence may be described via rate dependent cohesion and friction angle. Although the Coulomb parameters are, like the rate and state dependent parameters, empirical, they have a significant data base which may help in understanding the underlying processes they describe (e.g.; WhitMan and HeAly, 1962; JEWell, 1989; SwAN et al., 1989; WoOD, 1990; LAJTAI et al., 1991).

The purpose of this paper is to formulate a rate dependent Coulomb friction law and to explore the consequences of this law for the stress states developed during pervasive and localized shear. In particular, theoretical arguments and observations from experimental and natural faults indicate different stress states for distributed shear within a gouge zone and localized shear at a gouge-rock boundary or between bare rock surfaces. When coupled with a Coulomb friction law these differences suggest a possible explanation for displacement dependence of frictional behavior as observed in laboratory experiments (Figure 1) and on natural faults (e.g., WESNOUSKY, 1988, 1990) 


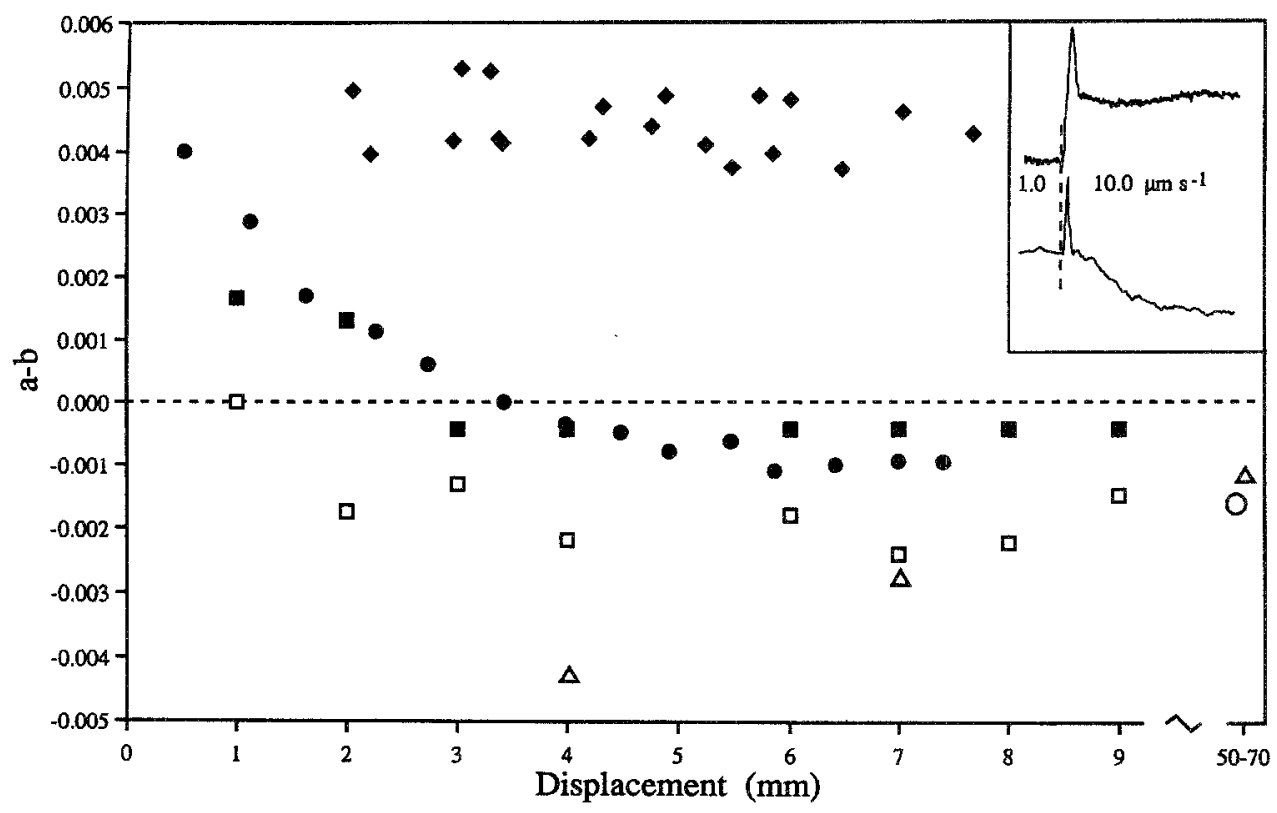

Figure 1

Displacement dependence of the friction rate parameter $(a-b)$ for sliding between initially bare surfaces and within gouge. Solid symbols show shear of a gouge layer between rough surfaces. Open symbols represent sliding between initially-bare rock surfaces or shear of a gouge layer between smooth surfaces. Note that for localized shear (open symbols) velocity weakening $(a-b<0)$ is observed from the beginning, whereas a transition from velocity strengthening to weakening occurs for shear of a gouge layer between rough surfaces. This transition does not occur in the upper data set ( ) for which shear did not localize at the gouge zone boundary and thus we infer that the transition from velocity strengthening to weakening is the result of a change from distributed to localized shear. Inset shows the effect of a velocity change from 1.0 to $10.0 \mu \mathrm{m} \mathrm{s}^{-1}$ on the coefficient of friction (plotted vs. displacement) for gouge (upper curve) and bare granite surfaces (data from MARONE et al., 1990). Data: 4-mm thick quartz gouge layers sheared between rough $(\approx 250 \mu \mathrm{m} \mathrm{rms})$ steel surfaces at $100 \mathrm{MPa}$ normal stress (MARONE et al., 1990). - 1-mm thick granite gouge sheared between 60 grit granite surfaces at $10 \mathrm{MPa}$ normal stress (DIETERICH, 1981). 3-mm thick granite gouge sheared between 60 grit granite surfaces at $10 \mathrm{MPa}$ normal stress (R3-710 data of Bregel et al., 1989). $\square$ 3-mm thick granite gouge sheared between 600 grit granite surfaces at $10 \mathrm{MPa}$ normal stress (S3-710 data of BrEGEL et al., 1989). $\triangle$ initially bare granite surfaces roughened with 60 grit and sheared at $27-84 \mathrm{MPa}$ normal stress (TULLIS and WEEKS, 1986). $O$ initially bare gabbro surfaces roughened with 60 grit and sheared at $5 \mathrm{MPa}$ normal stress (MARONE and COX, 1991). Uncertainty in all data is approximately \pm 0.001 .

\section{Distributed vs. Localized Shear}

A key parameter in the rate and state variable friction law is the steady-state velocity dependence of friction, $a-b=\Delta \mu / \Delta \ln V$, where $\mu$ is the coefficient of friction and $V$ is slip velocity (RuinA, 1983). Difficulties in making accurate laboratory measurements of $a-b$ have led to some inconsistency in reported values (e.g., DieTerich, 1981; LoCKNer et al., 1986; BLANPIED et al., 1987; BLANPIEd et al., 1988; TUllis et al., 1989); however, a common observation has been that shear 
between bare rock surfaces or along highly localized surfaces yields negative $a-b$, whereas positive values are obtained for pervasive shear within simulated fault gouge (Figure 1).

Localization of strain within gouge appears to affect the velocity dependence of friction. Gouge sheared between rough surfaces undergoes a transition with displacement from velocity strengthening $(a-b>0)$ to velocity weakening (Figure 1; BlANPIED et al., 1987; BlANPIED et al., 1988; Tullis et al., 1989; WeEKs et al., 1990) and shear localization occurs at the gouge rock boundary in these experiments (e.g. Dieterich 1981; M. L. BlanPIED pers. comm.). The displacement required to produce this transition scales with surface roughness, such that larger displacements are needed for rougher surfaces (Figure 1; BIEGEL et al., 1989). Furthermore, the transition is not observed when boundary shear localization is inhibited. In contrast, experiments on initially-bare rock surfaces show dominant velocity weakening for comparable displacements (Figure 1).

These observations suggest that the transition with displacement from velocity strengthening to velocity weakening in gouge (Figure 1) is related to shear localization at the gouge rock boundary. This is consistent with the well-known association between shear localization and unstable sliding in laboratory experiments (ENGELDER et al., 1975; BYERLEE and SUMMERS, 1976; LOGAN et al., 1979, 1981; SHIMAMOTO and LogAN, 1981; MoORE et al., 1986, 1989).

\section{Coulomb Constitutive Laws for Distributed and Localized Shear}

HовBS et al. (1990) derived relationships for Coulomb failure by distributed and localized shear. They argued that while localized shear is governed by the wellknown Coulomb criterion

$$
|\tau|=c+\sigma_{n} \tan \phi
$$

where $\tau$ and $\sigma_{n}$ are the shear and normal stress and $c$ and $\phi$ are cohesion and friction angle, the shear stress responsible for distributed shearing, such as within a thick gouge zone, is the maximum shear stress, $\tau_{\max }$, produced by the imposed stress state (Figure 2).

The stress state responsible for pervasive shearing occurs because the maximum shear strain rate is parallel to surfaces of simple shear and, for a Coulomb-Mohr material, the stress tensor is coaxial with the strain-rate tensor (HILL, 1960; TCHALENKO, 1970; RUDNICKI and RiCE, 1975; HobBs et al., 1990).

The experiments of MANDL et al. (1977) document such a stress state for shear within a granular gouge layer. Using photoelastic cells they found that during shear the maximum shear stress is parallel to the layer boundaries, and thus $\sigma_{1}$ is $45^{\circ}$ to the layer boundary (as in Figure 2d). MANDL et al.'s experiments were at relatively low normal stress ( $\leq 1 \mathrm{MPa}$ ), but the same conclusion is implied by the work of 


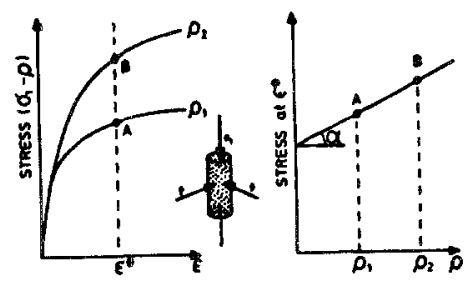

(a)

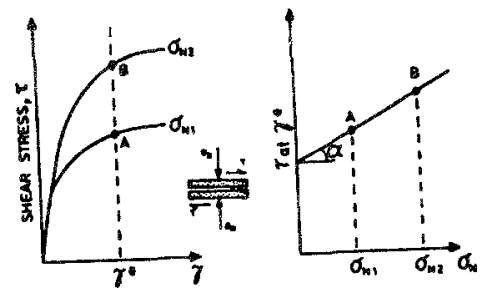

(b)

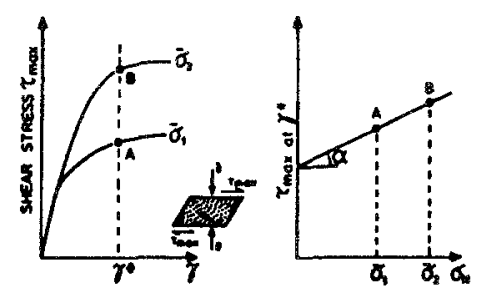

(c)

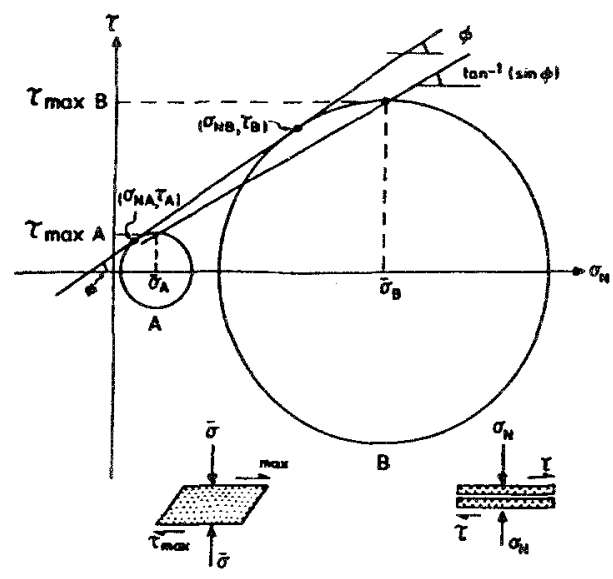

(d)

Figure 2

Pressure dependence of strength for distributed and localized shear. (a) Triaxial shortening experiment. Flow stress at constant shortening strain is plotted against pressure. The friction angle is given by $\tan ^{-1}\left\{\tan \alpha / 2(1+\tan \alpha)^{1 / 2}\right\}$. (b) Localized shearing such as for bare rock surfaces. Shear stress at a given shear strain is plotted against normal stress. The friction angle is $\alpha$. (c) Distributed shear within a thick gouge layer. Shear stress at a given shear strain is plotted against normal stress. The friction angle is $\sin ^{-1}(\tan \alpha)$. (d) Mohr diagrams for two stress states A and B. Stress state for distributed shear within a gouge layer is $\left(\tau_{\max }, \bar{\sigma}\right)$ where $\bar{\sigma}$ is the mean normal stress and $\tau_{\max }$ is the maximum shear stress. Stress state for shearing of bare rock surfaces is $\left(\sigma_{n}, \tau\right)$. The slope of the line connecting stress states for distributed shear is $(\sin \phi)$, whereas the slope of the line connecting stress states for localized shear is tan $\phi$. (Adapted from HoBBs et al., 1990.)

BYERLEE et al. (1978), who, working at normal stresses in the range 200-500 MPa, found that oblique (Riedel) shears form at a constant angle to the gouge zone boundary rather than to the macroscopic stress state. Since Riedel shears have been interpreted as Coulomb-type slip planes (e.g., MANDL et al., 1977), BYERLEE et al.'s result indicates that stress is reoriented within the gouge layer such that the maximum principal stress is $45^{\circ}$ to the gouge zone boundary. TCHALENKo (1970) 
reached the same conclusion, based on an analysis of secondary structures within shear zones of various scale. Each of these observations indicates coaxiality of strain rate and stress during shear of a granular layer. On the other hand, the coaxiality condition cannot be met for shear between bare rock surfaces or for generalized Coulomb deformation in which failure occurs at $\pm(45-\phi / 2)$ to the maximum principal stress (e.g., Figures 2a,b).

The different stress states for localized and pervasive shear have important implications for Coulomb friction laws. For localized shear, the cohesion and friction angle are obtained from (1) or in terms of the principal stress $\sigma_{2}$ (Figure 2)

$$
\tau=\frac{\sigma_{2} \sin \phi \cos \phi+c \cos ^{2} \phi}{1-\sin \phi} .
$$

However, in the case of pervasive shear, the line connecting stress states $\bar{\sigma}_{\mathrm{A}}$ and $\bar{\sigma}_{\mathrm{B}}$ has slope $\tan ^{-1}(\sin \phi)$, where $\bar{\sigma}$ is the mean normal stress (Figure 2). Thus, $c$ and $\phi$ are obtained from

$$
\tau_{\max }=\frac{\sigma_{2} \sin \phi+c \cos \phi}{1-\sin \phi}
$$

or in terms of the mean normal stress $\bar{\sigma}_{n}$

$$
\tau_{\max }=c \cos \phi+\sigma_{n} \sin \phi .
$$

The differences between (1) and (4) mean that, for a given material, frictional behavior may differ for localized shear, such as at a gouge-rock boundary, and pervasive shear within a gouge zone.

\section{Rate-dependent Coulomb Constitutive Laws}

By analogy with second-order variations in friction described by rate and state dependent friction laws (DIETERICH, 1979; RUINA, 1983), we may consider the effect on friction of rate dependent changes in cohesion and friction angle. We restrict attention to rate dependent changes in friction at constant normal stress.

Dividing Equations (1) and (4) by $\sigma_{n}$ yields a relation for the coefficient of friction in terms of cohesion, friction angle, and normal stress. The relations for localized and pervasive shear, respectively, are

$$
\begin{gathered}
\mu=\frac{c}{\sigma_{n}}+\tan \phi \\
\mu=\frac{c \cos \phi}{\sigma_{n}}+\sin \phi .
\end{gathered}
$$


Differentiating (5) and (6) with respect to $c$ and $\phi$ yields the change in coefficient of friction, $\Delta \mu$, due to perturbations in cohesion and friction angle. The relations for localized and pervasive shear, respectively, are as follows:

$$
\begin{gathered}
\Delta \mu=\frac{\Delta c}{\sigma_{n}}+\frac{\Delta \phi}{\cos ^{2} \phi}, \\
\Delta \mu=\frac{\cos \phi}{\sigma_{n}} \Delta c+\left(\cos \phi-\frac{c \sin \phi}{\sigma_{n}}\right) \Delta \phi,
\end{gathered}
$$

where $\Delta c=d c / d \log V$ and $\Delta \phi=d \phi / d \log V$.

To show the effect on friction of small, rate dependent changes in cohesion and friction angle we may plot contours of $\Delta \mu$ as a function of $\Delta c$ and $\Delta \phi$ (Figure 3). The plots are generated using Equations (7) and (8) and values for $c, \phi$, and $\sigma_{n}$ based on experimental data (Table 1).

For both distributed and localized shear, $\Delta \mu$ increases with increasing $\Delta c$ and $\Delta \phi$ (Figure 3). Higher values of $\phi$ yield smaller $\Delta \mu$ for given values of $\Delta c$ and $\Delta \phi$ (compare Figures $3 \mathrm{a}$ and $3 \mathrm{~d}$ ). For a given friction angle and normal stress, increased cohesion produces increased $\Delta \mu$ for distributed shear but, as indicated by Equation (7), cohesion does not affect $\Delta \mu$ for localized shear (compare Figures 3d and 3e). Higher normal stress reduces the effect on $\Delta \mu$ of both $\Delta c$ and $\Delta \phi$ (compare Figures $3 \mathrm{a}, 3 \mathrm{c}$, and $3 \mathrm{f}$ ).

For these values of cohesion, friction angle, and normal stress, there exists a region in which localized shear exhibits velocity weakening frictional behavior while pervasive shear exhibits velocity strengthening (shaded regions of Figure 3). Moreover, for $\Delta \phi<0$ localized shear generally yields smaller $\Delta \mu$ than pervasive shear, implying a greater tendency for instability (e.g., RuINA, 1983).

\section{Experimental Data Showing Rate-dependent Coulomb Constitutive Behavior}

Equations (5) and (6) may be used to derive values of cohesion and friction angle from experimental measurements of friction at different normal stresses. We used the data of MARONE et al. (1990) for shear of a gouge layer to derive: 1) values of cohesion and friction angle, and 2) slip-rate dependent changes in these parameters (Table 1).

An example of the effect on frictional strength of step changes in slip rate at three normal stresses is shown in Figure 4. The steady state change in friction for a decade change in slip rate ranges from 0.007 to 0.014 , decreasing with normal stress (MARONE et al., 1990). Cohesion and friction angle were obtained for slip velocities of 1 and 10 micron $\mathrm{s}^{-1}$ using Equation (6) and the steady state frictional strength at each velocity (Figure 4). To account for any displacement-dependent effects on the overall frictional strength we used data at comparable shear displacements (after correcting for apparatus distortion) from experiments at different normal stresses. In each case a linear fit to the shear strength-normal stress data 

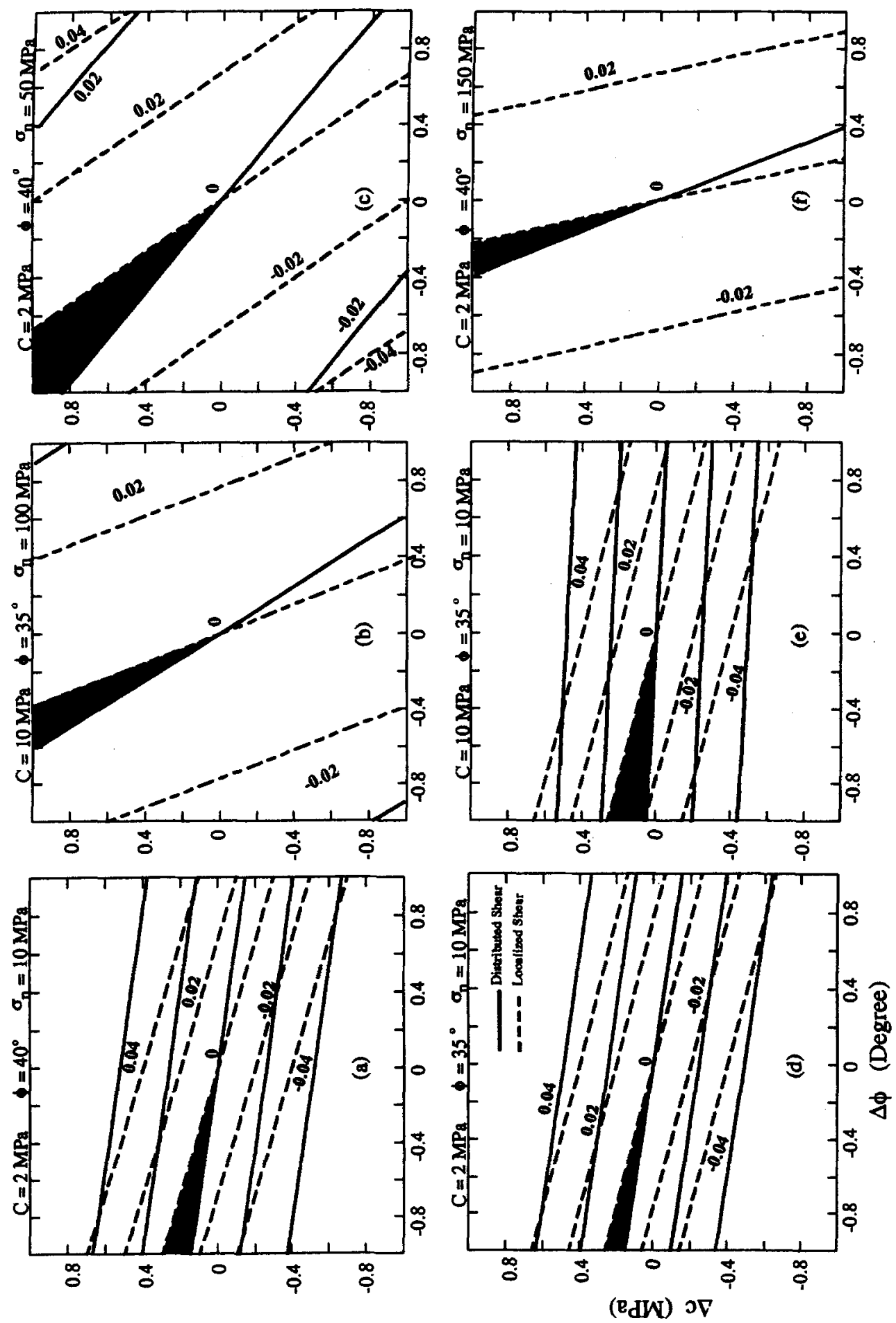
Table I

Rate dependent Coulomb constitutive parameters for distributed shear

\begin{tabular}{ccccccc}
\hline $\begin{array}{c}\text { Slip Velocity } \\
\mu \mathrm{m} \mathrm{s}^{-1}\end{array}$ & $\begin{array}{c}c^{o} \\
(\mathrm{MPa})\end{array}$ & $\begin{array}{c}\phi^{o} \\
(\text { Degree })\end{array}$ & $\begin{array}{c}c^{f} \\
(\mathrm{MPa})\end{array}$ & $\begin{array}{c}\phi^{f} \\
(\text { Degree })\end{array}$ & $\begin{array}{c}\Delta c \\
(\mathrm{MPa})\end{array}$ & $\begin{array}{c}\Delta \phi \\
(\text { Degree })\end{array}$ \\
\hline $1-10$ & 2.0 & 37.8 & 2.4 & 38.2 & 0.4 & 0.4 \\
$1-10$ & 1.4 & 38.5 & 2.1 & 38.8 & 0.7 & 0.3 \\
$1-10$ & 3.7 & 37.5 & 4.3 & 37.8 & 0.6 & 0.3 \\
$10-1$ & 2.7 & 38.5 & 2.1 & 38.2 & 0.6 & 0.3 \\
$10-1$ & 3.9 & 38.2 & 3.5 & 37.7 & 0.4 & 0.5 \\
\hline
\end{tabular}

Coulomb parameters for frictional sliding of simulated fault gouge at normal stresses of 50,100 , and $150 \mathrm{MPa}$ (see Figures 4 and 5). Parameters were obtained by applying the Coulomb law for pervasive shear (Equation 6) to data from the same velocity sequence (e.g., I to $10 \mu \mathrm{m} \mathrm{s}^{-1}$ ) at each normal stress. The superseripts $o$ and $f$ refer to values obtained at the initial and final velocities (given in the first column). $\Delta c=d c / d \log V$ and $\Delta \phi=d \phi / d \log V$ are the slip-rate dependence of cohesion and friction angle, respectively.

(Figure 5) gives a correlation coefficient of $>0.99$ and thus the use of a Coulombtype failure law, which is linear in normal stress, appears to be justified, at least for the limited data available.

For normal stress in the range $50-150 \mathrm{MPa}$, cohesion ranges from 1.4 to 4.3 $\mathrm{MPa}$ and friction angle from 37.5 to 38.8 degrees (Table 1). For a given velocity sequence the data show a consistent, positive rate dependence for both cohesion and friction angle (Table 1). The $\Delta c$ and $\Delta \phi$ values range from 0.4 to $0.7 \mathrm{MPa}$ and 0.3 to 0.5 degree, respectively. As expected, the velocity dependence of $c$ and $\phi$ is small compared with their absolute values (Figure 5, Table 1).

Rate-dependent Coulomb parameters were also obtained for shear between initially-bare granite surfaces. In this case shear is localized and thus Equation (1) applies. We used data from TULLIS and WEEKS (1986) for normal stresses of 28.6 to $57.4 \mathrm{MPa}$ and velocities of 1 and $10 \mu \mathrm{m} \mathrm{s}^{-1}$ (as reported in their Figure 6). TULLIS and WEEKS found velocity weakening and their data yield $\Delta \phi=-0.1^{\circ}$ and $\Delta c=-0.1 \mathrm{MPa}$ for $10 \times$ velocity changes. KILGORE et al. (1992) also measured frictional velocity dependence of bare granite surfaces. Their data cover normal

Figure 3

Contours of the velocity-dependence of friction $\Delta \mu$ for velocity-dependent cohesion $\Delta c$ and friction angle $\Delta \phi$ calculated using Equations (7) (localized shear) and (8) (distributed shear). In each plot the contour $\Delta \mu=0$ separates regions of velocity strengthening $(\Delta \mu>0)$ from velocity weakening for distributed and localized shear. The shaded areas show regions of $\Delta c, \Delta \phi$ space for which localized shear exhibits velocity weakening while distributed shear exhibits velocity strengthening. The dependence of $\Delta \mu$ on $\Delta c$ and $\Delta \phi$ varies with $c, \phi$, and $\sigma_{n}$ (a)-(f). Laboratory data show $\Delta \mu$ is in the range 0.01 to -0.01 for a $10 \times$ change in slip velocity (Figures 1 and 4$)$ and thus the range of $\Delta \mu$ values shown ( -0.04 to 0.04 ) represent velocity perturbations of $\leq 10^{4}$. 


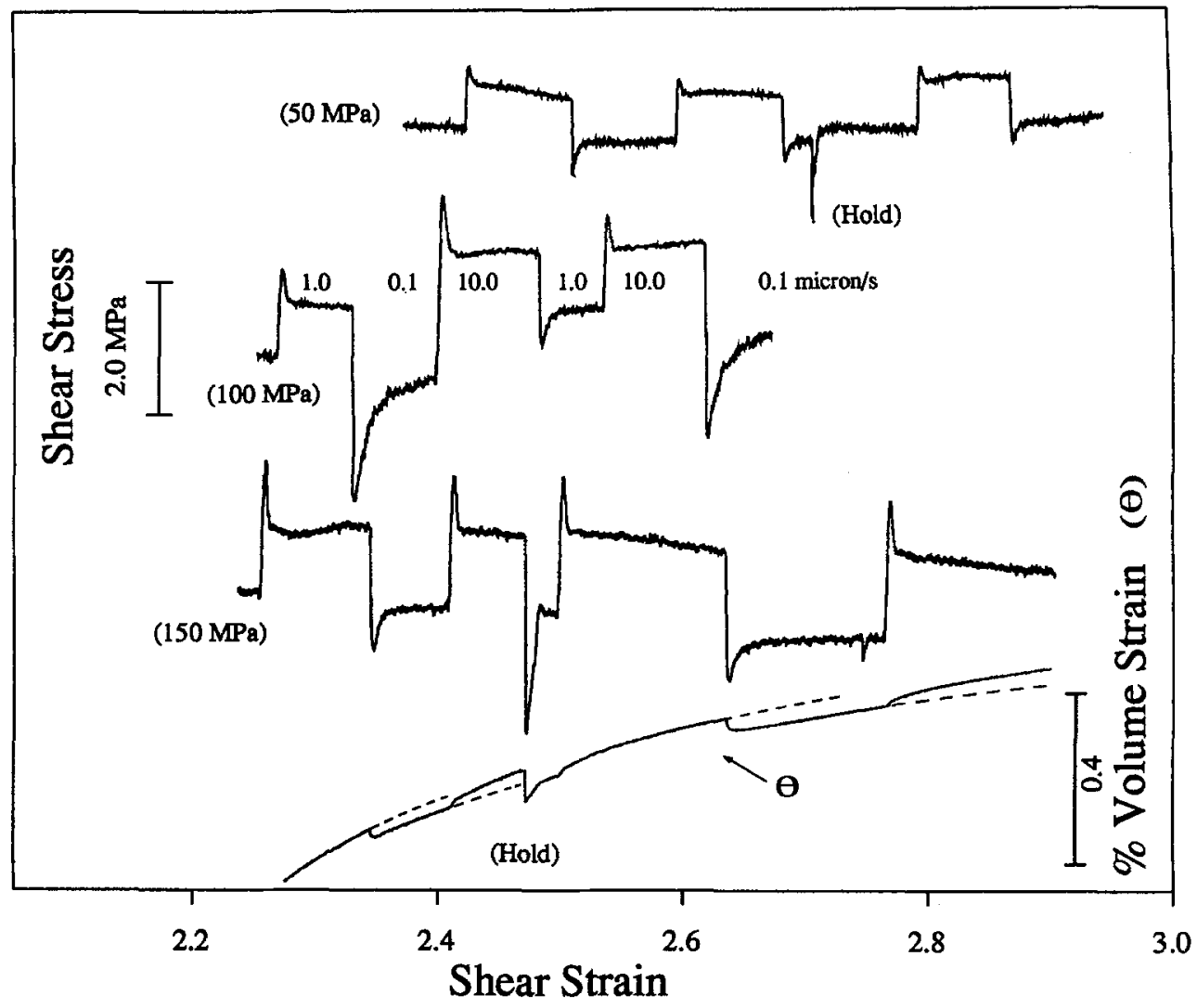

Figure 4

The effect on frictional strength (upper three curves) of step changes in slip rate at normal stresses of 50 , 100 and $150 \mathrm{MPa}$ [data are for distributed shear of a 4-mm thick quartz gouge layer (MARONE et al., 1990)]. The remotely-imposed slip rates are given at $100 \mathrm{MPa}$; in all other cases the slip rate was cycled between 1 and $10 \mu \mathrm{m} \mathrm{s}^{-1}$. Data at 1 and $10 \mu \mathrm{m} \mathrm{s}^{-1}$ were used to determine the slip-rate dependence of cohesion and friction angle (see Table 1). For the $150 \mathrm{MPa}$ data, the volume strain vs. shear strain record is shown for the same interval (dilation is positive).

stresses from 5 to $150 \mathrm{MPa}$ and yield $\Delta \phi=-0.2^{\circ}$ and $\Delta c=0 \mathrm{MPa}$ for velocities of 1 to $10 \mu \mathrm{m} \mathrm{s}^{-1}$. Thus, for localized shear $\Delta \phi$ shows negative velocity dependence and $\Delta c$ is neutral to slightly negative.

\section{State Dependence of Friction}

The evolution of $c$ and $\phi$ following a velocity change can be determined by casting the rate and state dependent friction law in terms of the Coulomb relations (5) and (6). Following RUINA's (1983) formulation, we have for pervasive shear

$$
c^{\prime} \cos \phi+\sin \phi=c_{o}^{\prime} \cos \phi_{o}+\sin \phi_{o}+a \ln \left(V / V_{*}\right)+b \psi
$$




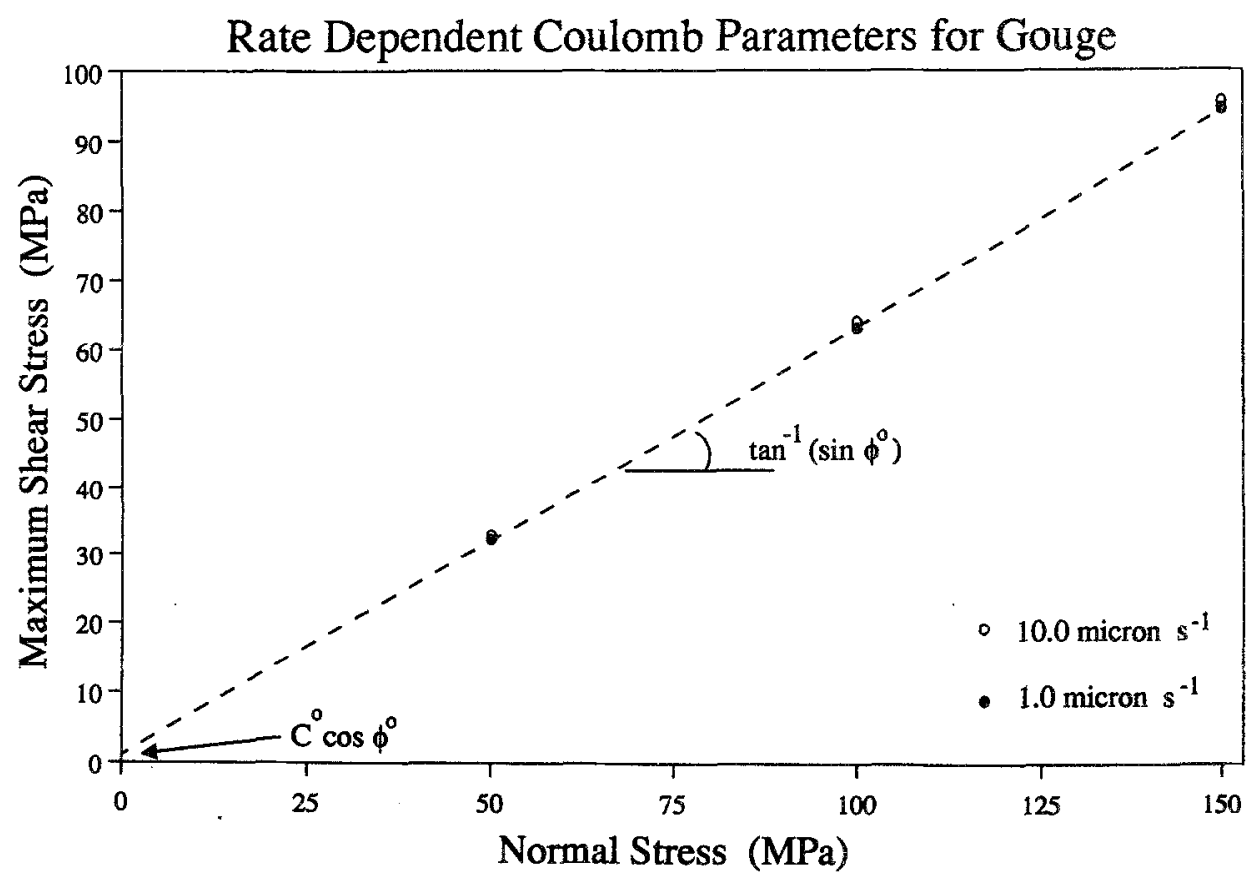

Figure 5

Normal stress dependence of frictional strength. Solid circies represent strength at 1.0 micron $\mathrm{s}^{-1}$ slip rate and open circles at 10.0 micron $\mathrm{s}^{-1}$ (e.g., Figure 4). Strength is slip-rate dependent, which indicates a slip-rate dependence of $c$ and $\phi$. The parameters $c$ and $\phi$ are obtained from a linear fit to the data according to Equation (6), which is the Coulomb failure law for pervasive shear of a gouge layer (see also Figure 2d). The dashed line shows the best fit to the 1.0 micron $\mathrm{s}^{-1}$ data. Uncertainty in the shear strength determinations is $\pm 0.05 \mathrm{MPa}$; for reference, the circles are $1.6 \mathrm{MPa}$ (shear stress) in diameter.

where $c^{\prime}=c / \sigma_{n}, V$ is slip velocity, $\psi$ is a state variable, and the terms $c_{o}^{\prime}, \phi_{o}$, and $V_{*}$ are constants. The state variable $\psi$ evolves following a change in slip velocity according to (RUINA, 1983):

$$
\frac{d \psi}{d t}=-\frac{V}{D c}\left[\psi+\ln \left(V / V_{*}\right)\right]
$$

where $D c$ is a characteristic distance over which friction evolves. Coupling Equations (9) and (10) with a relation describing elastic interaction between the deforming region and its surroundings yields the displacement dependence of $c$ and $\phi$.

Using measured $\Delta c$ and $\Delta \phi$ values for distributed shear (Table 1) we obtained values for $a, b$, and $D c$ by simultaneously fitting the numerical solution of Equations $(9-10)$ to friction data at two normal stresses (Figure 6a). Because Equation (9) is cast in terms of the Coulomb parameters, both numerical simulations are derived from the same values of $c$ and $\phi$ (Figure 6b). 

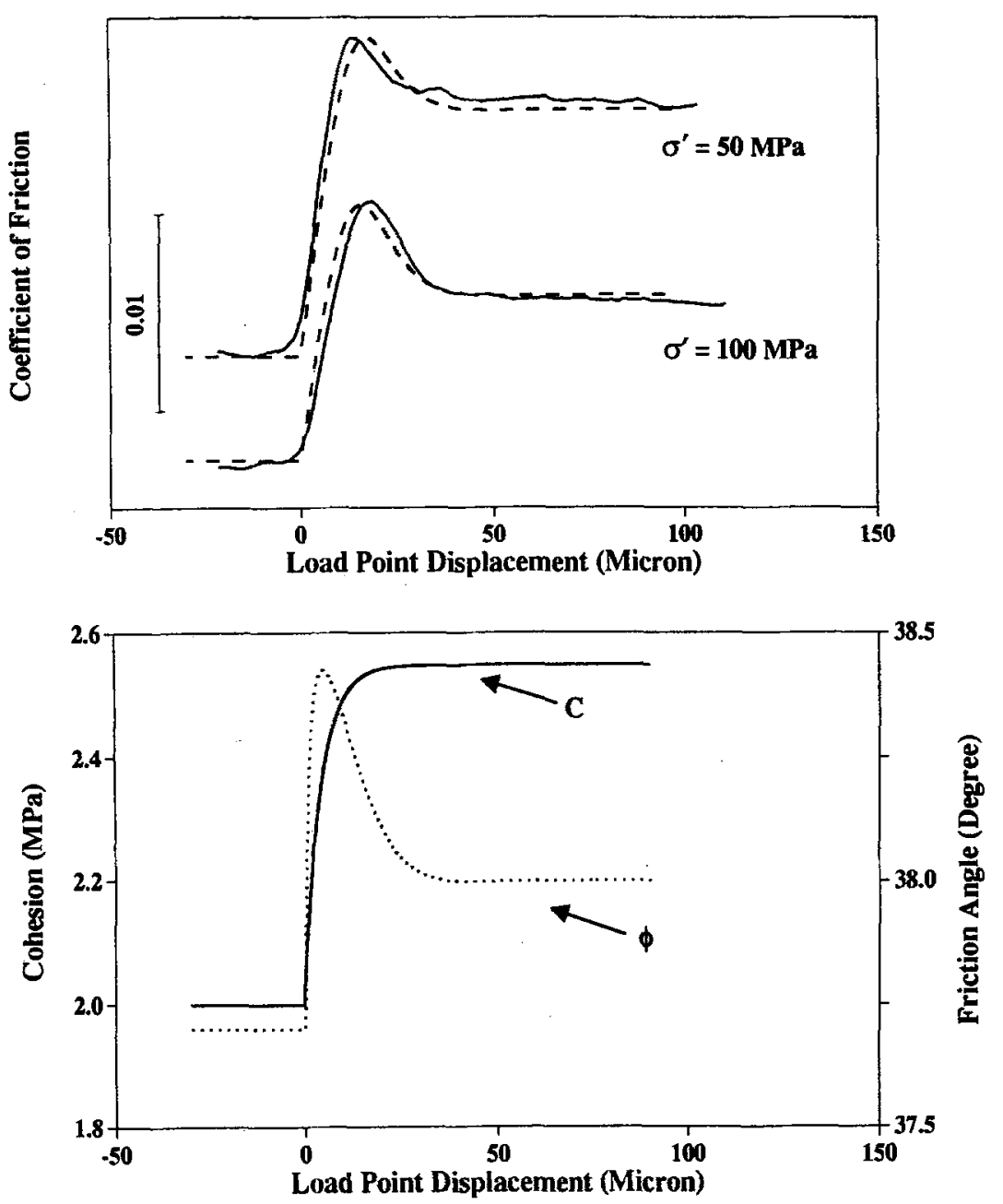

Figure 6

(a) Friction data (solid lines) and numerical simulations (dashed lines) for a step change in load point velocity from 1 to $10 \mu \mathrm{m} \mathrm{s}^{-1}$ (imposed at 0 displacement) at 50 and $100 \mathrm{MPa}$ normal stress (data from MARONE et al., 1990). The numerical simulations are solutions to Equations (9-10) coupled with a spring-slider model of elastic interaction between the deforming region and its surroundings. The simulations were done by fixing $\Delta c$ and $\Delta \phi$ at their measured values $(0.43 \mathrm{MPa}$ and 0.36 degree, respectively) and varying $a, b$, and $D c$ to simultaneously fit the friction data at both normal stresses. The simulations shown are for: $a=0.0094, b=0.0039$, and $D c=8.0 \mu \mathrm{m}$. (b) The effect of the velocity change on $c$ and $\phi$ as determined from the simulations in (a). The friction angle (dotted line) exhibits an immediate increase upon the increase in velocity followed by a displacement dependent decay, whereas cohesion evolves to a new higher value without exhibiting a peak and decay. 
The modeling indicates that $\phi$ exhibits an immediate increase upon a velocity increase followed by a displacement dependent decay, whereas cohesion evolves to a new, higher value without exhibiting a peak and decay (Figure 6b). As required by the experimental data, both cohesion and friction angle exhibit a steady state increase with velocity. We tested alternative forms of Equation (9), such as imposing a velocity and state dependence on cohesion and/or friction angle instead of on $\mu$, but the results were not significantly different than those shown in Figure 6 .

\section{Discussion}

Experimental data and theoretical considerations indicate different stress states (Figure 2) and frictional rate dependence (Figure 1) for distributed and localized shear. Since distributed shear implies strain hardening mechanisms, whereas localized shear implies strain weakening, contrasting macroscopic frictional behavior may be expected. However, what are the micro-mechanisms that produce these differences and how do they relate to the process of stress reorientation implied by the different stress states for distributed and localized shear?

To address these questions we need to better define the terms distributed and localized shear. The criteria we have used to distinguish between distributed and localized shear include friction characteristics (e.g., Figure 1) and end-member mechanical scenarios (Figure 2). Shear is assumed to be localized if it occurs along a surface (Figure $2 b$ ), whereas shear of a thick layer may be distributed pervasively or localized along a boundary-parallel surface within the zone (Figure 2d). Distributed shear and coaxiality of stress and strain rate imply rotation of the far field principal stress directions, and thus stress reorientation across a shear zone can be used to distinguish between distributed and localized shear.

Experimental data and observations of natural fault zones indicate stress reorientation within thick gouge (MANDL et al., 1977; TCHALENKO, 1970). The experiments of MANDL et al. show a direct link between stress rotation and shear localization. They found that during loading the maximum principal stress direction rotated to become $45^{\circ}$ to the shear zone boundary and that after a peak stress was reached (presumably indicating the onset of shear localization) the principal stress angle decreased, implying a stress field similar to that of localized shear.

We do not know of similar data that would demonstrate the dependence of stress reorientation on layer thicknesses, but stress cannot reorient within vanishingly thin layers. Furthermore, stress is presumably not reoriented in the case of shear localization at a gouge rock boundary or when strain is localized along narrow, through-going shear bands such as the Y Shears of LOGAN et al. (1979). Thus, stress reorientation of the type implied by Figure $2 \mathrm{~d}$ and Equation (4) is controlled in part by the width over which strain is accommodated (e.g., the shear band width, MüHLHAUS and VARDOULAKIS, 1987). 
If we accept that distributed shear involves stress rotation we are left with the question of why stress rotation occurs and what are the underlying micro-mechanical processes. One way to produce stress reorientation is via a contrast in material properties. Thus, stress reorientation is expected at the contact of a porous gouge layer with rock. The above arguments, however, imply that stress reorientation does not occur for thin layers, which indicates that stress reorientation requires a critical layer thickness. This is consistent with the moduli of thin, highly indurated gouge being insufficiently different from rock to effect a significant stress reorientation. Gouge layer thickness, shear band width, and particle size distribution are therefore key parameters for stress reorientation within shear zones.

\section{Rate-dependent Coulomb Laws for Distributed and Localized Shear}

The thickness over which shear takes place is a key factor producing stress rotation within a shear zone. Stress rotation, in turn, implies a modified form of the Coulomb criterion (Figure 2, Equation 4), and thus the Coulomb parameters are recovered from different criteria and the principal stresses for distributed shearing obey different relations than for localized shear.

Differences in the Coulomb criteria imply that failure in the two cases will occur at different angles to the far-field principal stresses. The angle between $\sigma_{1}$ and failure will be $45^{\circ}-\phi / 2$ for localized shear and $\phi / 2$ for distributed shear. Thus, $\phi$ as determined from the former relation and the orientation of failure surfaces within a shear zone will be smaller than the true $\phi$ of the material, which is consistent with the experimental results of TCHALENKO (1970), who found Riedel shears at $12^{\circ}$ and $7^{\circ}$ to $\sigma_{1}$ for clays with true friction angles of $23^{\circ}$ and $13^{\circ}$, respectively.

A further consequence of contrasting Coulomb laws for distributed and localized shear is that frictional rate dependence will differ for the same rate dependence of the Coulomb parameters. Of particular interest is the possibility of distributed shear exhibiting velocity strengthening frictional behavior while, for the same Coulomb parameters, localized shear exhibits velocity weakening (Figure 3). For reasonable values of normal stress, friction angle and cohesion, such a region exists for $\Delta \phi<0$ and $\Delta c>0$ (Figure 3).

Our analysis of experimental data, however, shows that neither set of rate dependent Coulomb parameters falls within this general region. Localized shear yields $\Delta \phi<0$ and $\Delta c \approx 0$, values that are near this region for low $\sigma_{n}$, but substantially outside this region for higher $\sigma_{n}$ (Figure 3). The parameters for distributed shear of gouge are within the velocity strengthening field for both types of shear. Within this field localized shear is expected to exhibit greater velocity strengthening than distributed shear.

The effect of differences in the stress states for distributed and localized shear is accounted for by the differences in the Coulomb criteria (Equations 7 and 8), and thus, to the extent that $\Delta \phi$ and $\Delta c$ are material parameters, the values 
recovered from pervasive or localized frictional sliding should be identical. Our analysis, however, shows this is not the case. Distributed shear exhibits a fundamentally different rate dependence of the friction angle and cohesion than localized shear. This presumably reflects inherent differences in the two cases; for example, significant dilation in the case of gouge would produce larger $\Delta \phi$ due to the relation between shear strength and dilation (MARONE et al., 1990; MARONE, 1991).
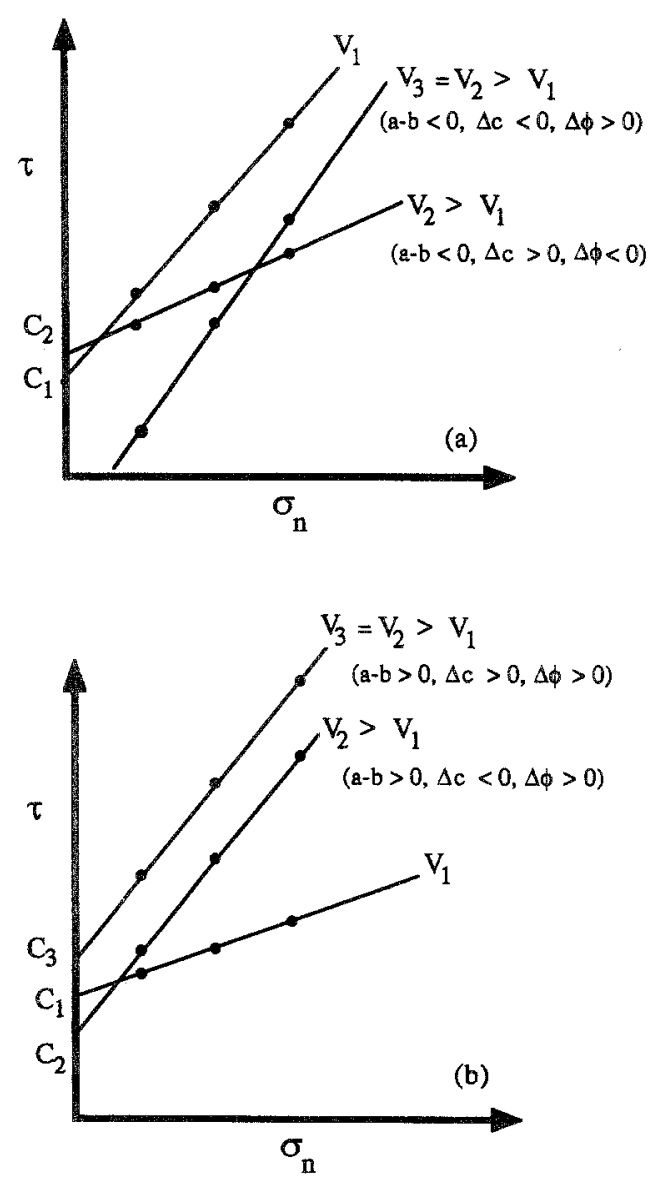

Figure 7

Sketch of the relation between the friction rate parameter $a-b$ and the rate dependent Coulomb parameters. Dots indicate frictional strength $(\tau)$ at different normal stresses $\left(\sigma_{n}\right)$ and slip velocities $(V)$. The relation between $a-b$ and $\Delta c, \Delta \phi$ depends on both the magnitude and normal stress dependence of $a-b$. (a) Two possibilities for producing velocity weakening are shown. For $V_{2}$, velocity weakening results from rate strengthening cohesion and rate weakening friction angle, whereas for $V_{3}$, velocity weakening is produced by $\Delta c<0$ and $\Delta \phi>0$. Data for $V_{2}$ show increasing $|a-b|$ with normal stress, whereas data for $V_{3}$ show the opposite. The same reasoning indicates that velocity strengthening can be produced by either rate strengthening or weakening $c$ and $\phi$ depending on the normal stress dependence of $|a-b|$. (b) Velocity strengthening with $|a-b|$ independent of normal stress. In this case $\Delta \phi>0$ is implied, but $\Delta c$ can be either positive or negative depending on $|a-b|$. 


\section{Relation Between the Friction Rate Parameter and Rate Dependent Coulomb Parameters}

It is important to note the complexity of the relation between the friction rate parameter $a-b$ and the rate dependent Coulomb parameters (Figure 7). Velocity weakening behavior can be produced by either positive or negative $\Delta \phi$ or $\Delta c$, depending on the magnitude and normal stress dependence of $a-b$ (Figure 7a). If $|a-b|$ is small and increases with normal stress ( $V_{2}$ case of Figure $\left.7 \mathrm{a}\right)$, rate strengthening cohesion and rate weakening friction angle are implied. On the other hand, if $|a-b|$ is large or if it decreases with normal stress ( $V_{3}$ case of Figure 7a), $\Delta c<0$ and $\Delta \phi>0$ are implied.

The same is true for velocity strengthening as indicated by the positive rate dependence of friction angle for gouge (Table 1) even though $a-b$ decreases with normal stress (MARONE et al., 1990). The geometry of Figure 7a indicates that $a-b>0$ can be produced by either rate strengthening cohesion and rate weakening friction angle or vice versa, depending on the magnitude and normal stress dependence of $a-b$. If $a-b$ is independent of normal stress (Figure 7b), then $\Delta \phi$ has the same sign as $a-b$, however, the sign of $\Delta c$ depends on the magnitude of $a-b$. For velocity strengthening with $a-b$ independent of normal stress, rate weakening cohesion is implied for small $a-b$, whereas large values of $a-b$ indicate $\Delta c>0$ (Figure $7 \mathrm{~b}$ ).

\section{Application to Natural Faults}

Laboratory friction data imply stable sliding for distributed shear within wide fault zones and potentially unstable behavior for narrowly localized slip. Our results indicate further differences in stability for distributed and localized shear on the basis of differences in the Coulomb failure criteria. The results, however, do not provide an independent estimate of the fault zone width at which a transition from distributed to localized shear is expected, since, as discussed above, this dimension depends on a number of factors. The behavior of natural faults, however, places some constraint on the transition width.

Several lines of evidence show a link between distributed shear, wide fault zones, and velocity strengthening frictional behavior: 1) Seismic and geologic evidence show that the San Andreas and related faults in central California undergo distributed shear within a zone several kilometers wide (FENG and MCEvILLY, 1983; MoNTGOMERY and JONES, 1992), which implies strain hardening mechanisms. Further, the work of MoONEY and GinsBurG (1986) implies that the presence of thick, low-velocity fault gouge promotes stable sliding, since they only observed thick $(>2 \mathrm{~km}$ ) low-velocity zones within aseismic portions of the San Andreas in central California and not within frictionally-locked sections. 2) Seismic evidence shows that faults evolve toward stable sliding with accumulated displacement, such that faults 
with large net offsets and wide gouge zones exhibit greater aseismic slip (WESNOUSKY, 1988, 1990). 3) Faults with well-developed gouge zones exhibit an upper stability transition, whereas faults with poorly developed or non-existent gouge zones do not (MARONE and SCHOLZ, 1988) and 4) earthquake afterslip and coseismic slip are significantly affected by the presence of a wide gouge zone (MARONE et al., 1991).

These observations are consistent with laboratory data showing velocity strengthening for distributed shear (MARONE et al., 1990). Moreover, high-resolution crustal structure and hypocentral locations within the San Andreas fault zone at Parkfield show that the shear zone, defined by an anomolously high $V p / V s$, narrows with depth, going from $\approx 5 \mathrm{~km}$ in width at the surface to $<1 \mathrm{~km}$ at a depth of 4-5 km (MICHELINI and MCEVILLY, 1991). When coupled with the data of MARONE and Scholz (1988) showing a stability transition at 3-5 km depth, this implies that localized behavior occurs for shear within a zone of less than $\approx 1 \mathrm{~km}$.

\section{Conclusions}

While it has long been recognized that the maximum principal stress for simple shear is boundary controlled, the detailed conditions under which this applies and the implications for a Coulomb-type failure criterion have not been widely discussed. We show that a number of observations indicate different stress states for distributed shear within a layer and localized shear such as along a gouge rock boundary or between bare rock surfaces. We also present evidence suggesting a link between changes in frictional behavior, stress reorientation, and shear localization. Differences in the Coulomb friction laws for distributed and localized shear offer an explanation for stress reorientations and contrasts in frictional behavior.

The friction laws proposed here allow recovery of the Coulomb parameters of cohesion and friction angle for both distributed and localized shear. In the context of these laws, frictional rate dependence is described via rate dependence of the Coulomb parameters. Differences in the stress states for distributed and localized shear can lead to different frictional rate dependence for the same rate dependence of the Coulomb parameters.

Our analysis shows that the stress state within a shear zone, and in particular stress reorientation of the type implied by Figure $2 \mathrm{~d}$ and Equation (4), is controlled in part by the width over which strain is accommodated. Thus, gouge layer thickness and shear band width are key parameters producing differences between distributed and localized shear. Observations from natural faults suggest that distributed shear and velocity strengthening behavior occur where shear is accommodated within a thick $(\approx 1 \mathrm{~km}$ or greater) fault zone. 


\section{Acknowledgements}

We thank M. Blanpied and C. Scholz for comments and discussions on the utility of rate dependent Coulomb laws. CM would like to acknowledge support from the Berkeley Seismographic Station, NSF grant 91-18249, and IGPP.

\section{REFERENCES}

Biegel, R. L., Sammis, C. G., and Dieterich, J. H. (1989), The Frictional Properties of a Simulated Gouge Having a Fractal Particle Distribution, J. Struct. Geology 11, 827-846.

Blanpied, M. L., Tullis, T. E., and WeEKs, J. D. (1987), Contrasting Velocity Dependence of Granite Friction: Initially Bare Surfaces vs. Simulated Gouge, EOS, Trans. Am. Geophys. Un. 68, 1478.

Blanpied, M. L., Tullis, T. E., and Weeks, J. D. (1988), Textural and Mechanical Evolution of Granite Gouge in High-displacement Sliding Experiments, EOS, Trans. Am. Geophys. Un. 69, 1478.

Blanpied, M. L., LoCKNER, D. A., and BYERLEe, J. D. (1991), Fault Stability Inferred from Granite Sliding Experiments at Hydrothermal Conditions, Geophys. Res. Lett. 18, 609-612.

Byerlee, J., and Summers, R. (1976), A Note on the Effect of Fault Gouge Thickness on Fault Stability, Int. J. Rock Mech. Min. Sci. Geomech. Abstr. 13, 35-36.

Byerlee, J., Muachin, V., Summers, R., and Voevoda, O. (1978), Structures Developed in Fault Gouge During Stable Sliding and Stick-slip, Tectonophysics 44, 161-171.

Chester, F. M., and Higgs, N. G. (1992), Multimechanism Friction Constitutive Model for Ultrafine Quartz Gouge at Hypocentral Conditions, J. Geophys. Res. 97, 1859-1870.

Cox, S. J. D., Velocity dependent friction in a large direct shear experiment on gabbro. In Deformation Mechanisms, Rheology, and Tectonics (eds. R. J. Knipe, and E. H. Rutter) (Geol. Soc. London Spec. Pup. 54, 1990) pp. 63-70.

Dieterich, J. H. (1979), Modeling of Rock Friction: 1. Experimental Results and Constitutive Equations, J. Geophys. Res. 84, 2161-2168.

DiETERICH, J. H., Constitutive properties of faults with simulated gouge. In Mechanical Behavior of Crustal Rocks (eds. N. L. Carter, M. Friedman, J. M. Logan, and D. W. Stearns) (AGU Monograph 24, 1981) pp. $103-120$.

DiETERICH, J. H., A model for the nucleation of earthquake slip. In Earthquake Source Mechanics (eds. S. Das, J. Boatwright, and C. H. Scholz) (AGU Monograph 37, 1986) pp. 37-47.

DiETERICH, J. H., and CONRAD, G. (1984), Effect of Humidity on Time and Velocity-dependent Friction in Rocks, J. Geophys. Res. 89, 4196-4202.

Engelder, J. T., Logan, J. M., and Handin, J. (1975), The Sliding Characteristics of Sandstone on Quartz Fault-gouge, Pure and Appl. Geophys. 113, 69-86.

Feng, R., and McEvilly, T. V. (1983), Interpretation of Seismic Reflection Profiling Data for the Structure of the San Andreas Fault Zone, Bull. Seismol. Soc. Am. 73, 1701-1720.

Frank, F. C. (1965), On Dilation in Relation to Seismic Sources, Rev. Geophys. 3, 485-503.

Handin, J. (1969), On the Coulomb-Mohr Failure Criterion, J. Geophys. Res. 74, 5343-5348.

HiLl, R., The Mathematical Theory of Plasticity (Oxford 1960).

HobBs, B. E., Ord, A., and MARone, C., Dynamic Behaviour of Rock Joints, Proc. Int. Symp. on Rock Joints (eds. N. R. Barton, and O. Stephansson) (Loen, Norway 1990) pp. 435-445.

JeWell, R. A. (1989), Direct Shear Tests on Sand, Géotechnique 39, 309-322.

Kílgore, B. D., and Dieterich, J. H. (1991), New Experimental Technique for Direct Visual Observation of Micro-mechanical Fault Processes, EOS, Trans. Am. Geophys. Un. 72, 458.

Kilgore, B. D., Blanpied, M. L., and Dieterich, J. H. (1992), Velocity and Normal Stress Dependent Friction of Granite, submitted to Geophys. Res. Lett.

LaJTAI, E. Z., Duncan, E. J., and CARTER, B. J. (1991), The Effect of Strain Rate on Rock Strength, Rock Mech. and Rock Eng. 24, 99-109.

LinKer, M. F., and Dieterich, J. H. (1992), Effects of Variable Normal Stress on Rock Friction: Observations and Constitutive Equations, J. Geophys. Res. 97, 4923-4940. 
Lockner, D. A., Summers, R., and Byerlee, J. D. (1986), Effects of Temperature and Sliding Rate on Frictional Strength of Granite, Pure and Appl. Geophys. 124, 445-469.

Logan, J. M., Friedman, M., Higgs, N., Dengo, C., and Shimamoto, T. (1979), Experimental Studies of Simulated Gouge and Their Application to Studies of Natural Fault Zones, Analyses of Actual Fault Zones in Bedrock, U.S. Geol. Surv. Open File Rep. 79-1239, 305-343.

LogAN, J. M., HigGS, N. G., and Friedman, M., Laboratory studies on natural gouge from the U.S.G.S. Dry Lake valley No. 1 well, San Andreas Fault Zone. In Mechanical Behavior of Crustal Rocks (eds. N. L. Carter, M. Friedman, J. M. Logan, and D. W. Stearns) (AGU Monograph 24, 1981) pp. 121-131.

MANDL, G., DE JONG, L. N. J., and MALtha, A. (1977), Shear Zones in Granular Material: An Experimental Study of their Structure and Mechanical Genesis, Rock Mech. 9, 95-144.

Marone, C. (1991), A Note on the Stress-dilatancy Relation for Simulated Fault Gouge, Pure and Appl. Geophys. 137, 409-419.

Marone, C., and Cox, S. J. D. (1991), Effects of Surface Roughness and Displacement on the Frictional Constitutive Behavior of Gabbro, EOS, Trans. Am. Geophys. Un. 71, 457.

MARone, C., and Scholz, C. H. (1988), The Depth of Seismic Faulting and the Upper Transition from Stable to Unstable Slip Regimes, Geophys. Res. Lett. 15, 621-624.

Marone, C., and Scholz, C. H. (1989), Particle-size Distribution and Microstructures Within Simulated Fault Gouge, J. Struct. Geo. 11, 799-814.

Marone, C., Raleigh, C. B., and Scholz, C. H. (1990), Frictional Behavior and Constitutive Modeling of Simulated Fault Gouge, J. Geophys. Res. 95, 7007-7025.

Marone, C., Scholz, C. H., and Bilham, R. (1991), On the Mechanics of Earthquake Afterslip, J. Geophys. Res. 96, 8441-8452.

MrChelini, A., and McEvilly, T. V. (1991), Seismological Studies at Parkfield. I. Simultaneous Inversion for Velocity Structure and Hypocenters Using Cubic B-splines Parameterization, Bull. Seismol. Soc. Am. 81, 524-552.

Montgomery, D. R., and Jones, D. L. (1992), How wide is the Calaveras Fault Zone?-Evidence for Distributed Shear along a Major Fault in Central California, Geology 20, 55-58.

Moore, D. E., Summers, R., and Byerlee, J. D. (1986), The Effects of Sliding Velocity on the Frictional and Physical Properties of Heated Fault Gouge, Pure and Appl. Geophys. 124, 31-52.

MoOre, D. E., Summers, R., and BYERLEe, J. D. (1989), Localization of Deformation during Stick-slip and Stable Sliding in Granite, EOS, Trans. Am. Geophys. Un. 70, 1303.

Mühlhaus, H. B., and Vardoulakis, I. (1987), The Thickness of Shear Bands in Granular Materials, Géotechnique 37, 271-283.

RiCE, J. R., and GU, J.-C. (1983), Earthquake Aftereffects and Triggered Seismic Phenomena, Pure and Appl. Geophys. 121, 187-219.

ReINEN, L. A., Weeks, J. D., and Tullis, T. E. (1992), Interaction of Two Mechanisms during Frictional Sliding of Serpentinite, EOS, Trans. Am. Geophys. Un. 73, 310.

RUDNICKI, J. W., and RICE, J. R. (1975), Conditions for the Localization of Deformation in Pressure-sensitive Materials, J. Mech. Phys. Solids 23, 371.

Ruina, A. (1983), Slip Instability and State Variable Friction Laws, J. Geophys. Res. 88, 10359-10370.

SCHOLz, C. H. (1988), The Critical Slip Distance for Seismic Faulting, Nature 336, 761-763.

Shimamoto, T. (1986), Transition between Frictional Slip and Ductile Flow for Halite Shear Zones at Room Temperature, Science 231, 711-714.

Shimamoto, T., and Logan, J. M. (1981), Effects of Simulated Fault Gouge on the Sliding Behavior of Tennessee Sandstone: Nonclay Gouges, J. Geophys. Res. 86, 2902-2914.

Steacy, S. J., and Sammis, C. G. (1992), A Damage Mechanics Model for Fault Zone Friction, J. Geophys. Res. 97, 587-594.

Swan, G., Cook, J., Bruce, S., and Meehan, R. (1989), Strain Rate Effects in Kimmeridge Bay Shale, Int. J. Rock Mech. Min. Sci. and Geomech. Abst. 26, 135-149.

TChalenko, J. S. (1970), Similarities between Shear Zones of Different Magnitudes, Geol. Soc. Am. Bull. $81,1625-1640$.

TSE, S. T., and RICE, J. R. (1986), Crustal Earthquake Instability in Relation to the Depth Variation of Frictional Slip Properties, J. Geophys. Res. 91, 9452-9472. 
Tullis, T. E., and WeEks, J. D. (1986), Constitutive Behavior and Stability of Frictional Sliding of Granite, Pure and Appl. Geophys. 124, 383-414.

Tuldis, T. E., Blanpied, M. L., and WeEks, J. D. (1989), The Velocity Dependence of Granite Friction with and without Simulated Gouge, EOS, Trans. Am. Geophys. Un. 70, 1302.

Weeks, J. D., Beeler, N. M., Tullis, T. E., and Reinen, L. A. (1990), Velocity Dependence of Frictional Behavior of Simulated Granite Gouge to Large Displacement, EOS, Trans. Am. Geophys. Un. 71, 1478.

WeSNOUSKy, S. G. (1988), Seismological and Structural Evolution of Strike-slip Faults, Nature 335, $340-343$.

WeSNousky, S. G. (1990), Seismicity as a Function of Cumulative Geologic Offset: Some Observations from Southern California, Bull. Seismol. Soc. Am. 80, 1374-1381.

Whrtman, R. V., and Healy, K. A. (1962), Shear Strength of Sands during Rapid Loadings, J. Soil Mech. Fdns Div. ASCE 88, 99-133.

Wong, T.-f., Gu, Y., Yanagidani, T., and Zhao, Y., Stabilization of faulting by cumulative slip. In Fault Mechanics and Transport Properties of Rock (eds. B. Evans, and T.-f. Wong) (Academic Press Ltd 1991) pp. 119-143.

WooD, D. M., Soil Behaviour and Critical State Soil Mechanics (Cambridge 1990) $462 \mathrm{pp}$.

(Received July 23, 1992, accepted September 20, 1992) 